\title{
RESILIÊNCIA: CONTRIBUIÇÕES E DESAFIOS PARA O ESTUDO DO DESENVOLVIMENTO DAS REGIÕES
}

\author{
Clécio Azevedo da SiLva ${ }^{1}$ \\ RUDINEI KOCK EXTERCKOTER ${ }^{2}$ \\ Universidade Federal de Santa Catarina
}

\begin{abstract}
Resumo: Resiliência é um conceito muito utilizado nas ciências ecológicas e diz respeito à capacidade de um ecossistema de resistir a choques externos, se adaptar e responder a eles ao invés de simplesmente definhar e morrer. Sua acolhida pelas áreas de geografia econômica e afins é recente e pretende discutir a capacidade das regiões em se antecipar, se preparar, responder e se recuperar de uma perturbação social e/ou econômica. Contudo, sua contribuição para a compreensão do processo de desenvolvimento ainda carece de aprofundamento teórico e maior exame crítico, estando sujeita a inúmeros questionamentos. Diante disso, este artigo apresenta os resultados de uma pesquisa bibliográfica que objetiva elencar os desafios contidos na migração do conceito de resiliência para os estudos sobre desenvolvimento regional, bem como mapear a produção científica gerada sobre esse tema. Os resultados demonstram que, mesmo apresentando sérios limites, a noção de resiliência é promissora para o entendimento da dinâmica regional e já vem aparecendo de forma destacada nas bases de dados sobre a literatura específica.
\end{abstract}

Palavras-chave: Resiliência Regional; Desenvolvimento; Adaptação.

\section{RESILIENCE: CONTRIBUTIONS AND CHALLENGES FOR THE STUDY OF THE DEVELOPMENT OF THE REGIONS}

Abstract: Resilience is a concept widely used in ecological sciences and relates to the ability of an ecosystem to withstand external shocks, adapt and respond to these rather than simply wither and die. Its reception in the area of economic geography is recent and discusses the regions' ability to anticipate, prepare, respond and recover from a social and/or economic disorder. However, its contribution to the understanding the development process still lacks theoretical depth and more critical examination.

\footnotetext{
${ }^{1}$ Doutorando em Geografia pela Universidade Federal de Santa Catarina e Professor Mestre do Instituto Federal Catarinense - Campus Concórdia. Contato: rudinei@ifc-concordia.edu.br.

${ }^{2}$ Professor Associado do Departamento de Geociências da Universidade Federal de Santa Catarina. Contato: clecio@cfh.ufsc.br.
} 
Thus, this article presents the results of a literature survey and aimed to list the challenges contained in the migration of the concept of resilience for studies of regional development, as well as map the scientific production generated about this topic. The results demonstrate that even with limits, the notion of resilience is promising to understanding the regional dynamics, and has been appearing prominently in the databases about the specific literature.

Key words: Regional Resilience; Development; Adaptation.

\section{Introdução}

Ao longo do tempo, diversos autores com enfoques teóricos variados têm procurado responder como as regiões crescem, se reestruturam economicamente e respondem aos períodos de crise. O processo de desenvolvimento econômico não ocorre de maneira igual e simultânea em toda parte, e entender por que algumas regiões conseguem se desenvolver e outras não tem sido um tema desafiador para a teoria do desenvolvimento regional. O problema reside no fato de que cidades, regiões ou territórios não são apenas suportes passivos de localização de atividades econômicas, mas operam o desenvolvimento como âmbitos espaciais ativos, assumindo certo protagonismo na decisão dos seus destinos. Pergunta-se: algumas regiões seriam capazes de se desenvolver sem depender da redistribuição do crescimento econômico a partir de outras mais urbanizadas e/ou industrializadas? $\mathrm{Ou}$, quais seriam os motivos para que algumas regiões dentro dos países apresentem melhor resposta aos ciclos econômicos?

$\mathrm{Na}$ última década, os enfoques que se referem aos chamados territórios inovadores têm sido destacados (MÉNDEZ, 2002). O conceito de inovação é entendido por tais abordagens como "a capacidade de gerar e incorporar conhecimentos para dar respostas criativas aos problemas do presente (...)" (MÉNDEZ, 2002, p. 64). Assim, ao se mencionar o território inovador, faz-se referência aos territórios em que seus atores e instituições são capazes de gerar e incorporar conhecimentos para dar respostas criativas aos desafios que se apresentam.

Pecqueur (2005) reconhece a importância da inovação para o processo de desenvolvimento, mas alerta que, no atual contexto de globalização, as soluções liberais, situadas apenas no quadro macroeconômico, não parecem ser suficientes para produzir soluções inovadoras que respondam às necessidades do desenvolvimento. Segundo este autor, há a necessidade de se mobilizar os atores locais na elaboração de estratégias de adaptação aos limites externos, com base na identificação de aspectos ligados à identidade cultural e territorial. Da mesma forma, Méndez (2002) destaca a importância exercida pela proximidade física e cultural na criação de redes capazes de transmitir saberes tácitos, não formalizados e dificilmente decodificáveis, mas fundamentais para a geração e difusão de inovações.

Para esses pesquisadores, os processos de inovação levariam a estratégias de 
adaptação na medida em que este processo é reativo em relação à globalização. Tais reflexões permitiram a emergência do debate sobre a existência de uma resiliência regional, que pode conter uma promissora contribuição para o entendimento de como as regiões conseguem se adaptar e suportar as crises de diferentes ordens sem colapsar.

Diante disso, este artigo apresenta os resultados de uma pesquisa bibliográfica destinada a aprofundar o entendimento sobre a origem e a construção do conceito de resiliência regional, bem como, avaliar a produção científica gerada sobre esse tema. Para tanto, o artigo contém duas seções: a primeira, dedicada a apresentar a construção do conceito de resiliência no debate sobre o desenvolvimento, confrontando as perspectivas construídas por vários autores nos últimos anos; e a segunda, que se dedica ao mapeamento da literatura produzida até o momento, identificando as principais questões abordadas e os centros de produção acadêmica.

\section{A construção do conceito de resiliência no desenvolvimento regional}

O uso da noção de resiliência vem emergindo, nos últimos anos, na agenda do debate sobre desenvolvimento regional através de cientistas sociais, gestores públicos e organizações, em diferentes países. Curiosamente, o primeiro uso da palavra resiliência em trabalhos científicos é creditado a Francis Bacon, em 1625, com a publicação de um compêndio de escritos sobre história natural, o Sylva Sylvarum (ALEXANDER, 2013). Nos dois séculos seguintes, o termo continuou sendo usado em diferentes línguas e com significados variados, até ganhar destaque, em 1858, como uma noção da física de materiais aplicada à engenharia mecânica (BRANDÃO et al., 2011; MÉNDEZ, 2012; ALEXANDER, 2013). Posteriormente, a noção de resiliência foi introduzida em outros campos da ciência, como Psicologia e Ecologia.

Enquanto os físicos e engenheiros usavam o "módulo de resiliência" como base para calcular a quantidade máxima de energia que um dado material pode absorver ao ser submetido a determinado impacto, deformando-se sem se romper e voltando, posteriormente à forma primitiva; na Psicologia, de modo geral, a resiliência era usada para descrever e interpretar as possíveis razões pelas quais indivíduos que enfrentam situações traumáticas semelhantes podem mostrar comportamentos distintos que afetam diretamente a sua capacidade de recuperação pós-trauma (MENDÉZ, 2012).

Já nas ciências ecológicas, a resiliência ganhou destaque com a publicação do artigo de C. S. Holling, intitulado Resilience and stability of ecological systems, em 1973. Com isso, a resiliência passou a ser usada para descrever a capacidade que certos sistemas ambientais e organismos têm de serem menos vulneráveis, ou de resistir e responder a condições adversas voltando ao equilíbrio depois de uma

perturbação (HOLLING, 1973). O processo de contínua complexificação e 
ampliação do conceito resultou também na sua incorporação na literatura sobre gestão de desastres, particularmente, no contexto do desenvolvimento de medidas para atender situações de emergência, inclusive desastres ambientais e ataques terroristas (MANYENA, 2006; COAFFEE et al., 2008).

Nas ciências sociais, a noção foi introduzida pela Antropologia, ao aludir-se à hipótese de uma "flexibilidade adaptativa" por parte das comunidades tradicionais em seu encontro com a sociedade moderna, o que a delimitou conceitualmente como um recurso analítico para os enfoques estruturalistas (FORD \& EMERY, 2008).

Mais recentemente, a noção de resiliência vem chamando a atenção da Economia e da Geografia econômica, em especial na literatura que debate o desenvolvimento regional. Conforme argumenta Bristow (2010), é com a chamada "crise tripla" (recessão global, mudanças climáticas e dependência do petróleo - a qual tem causado grande preocupação devido às consequências materiais potencialmente desastrosas, tanto na forma de restrições de recursos (especialmente a segurança alimentar) quanto na incapacidade do sistema atual para gerenciar a sustentabilidade financeira e ecológica global - que a noção de resiliência ganha força.

\section{A migração do conceito para o desenvolvimento regional}

Para Hopkins (2008) e Bristow (2010), a inclusão da resiliência nos estudos regionais contribui para reconhecer a importância dos processos políticos e sociais sem eliminar o econômico, além de considerar que em diferentes lugares as pessoas se comportam e pensam de forma diferente, ou seja, as regiões evoluem de forma diferente. Portanto, existe um interesse crescente na busca de uma abordagem mais sistêmica, que enfatize e procure compreender o caráter mais amplo, mais qualitativo do desenvolvimento regional, em oposição ao desempenho econômico ou simplesmente ao crescimento. É sob este contexto do pensamento acadêmico que se admitiu a migração do conceito para a teoria do desenvolvimento regional.

Segundo Simmie e Martin (2010), o conceito vem sendo explorado, principalmente, em referência à capacidade de um sistema socioeconômico local para recuperar-se de um choque ou ruptura. Tanto que Foster (2007, p. 14) define resiliência regional "como a capacidade de uma região para antecipar, preparar, responder e se recuperar de uma perturbação". Hill et al. (2008) veem a resiliência como a capacidade de uma região de recuperar-se com êxito de choques (perturbações) na economia que ameaçam jogá-la fora de seu caminho de crescimento. Já Hopkins (2008) e Hudson (2009) conceituam resiliência como a capacidade de um sistema para absorver perturbações e reorganizar-se enquanto passa por uma mudança, de modo que ainda mantenha basicamente a mesma estrutura, função e feedbacks. Ou ainda, Ashby et al. (2009), que conceituam resiliência como a capacidade da região experimentar o sucesso econômico que seja socialmente inclusivo, que trabalhe dentro dos limites ambientais e que possa 
promover saltos econômicos.

Bristow (2010) avalia que essas várias definições de resiliência são fortemente inspiradas nas ciências ecológicas, pois, afinal, se referem à capacidade de um ecossistema (e as pessoas e as comunidades que dele dependem) para resistirem a choques externos, como incêndios florestais, se adaptarem e responderem a estes ao invés de simplesmente definharem e morrerem. Este olhar também é compartilhado por pesquisadores como Hudson (2009), Pendall et al. (2009), Christopherson et al. (2010), Pike et al. (2010), Simmie e Martin (2010), os quais ainda alertam para o risco dessa abordagem, considerada muitas vezes funcionalista e excessivamente inspirada nos processos naturais para explicar o desenvolvimento regional.

Para Hudson (2009), esses riscos podem ser minimizados desde que se analise a resiliência em um contexto interdisciplinar, no qual a compreensão das relações complexas entre as pessoas e a natureza é fundamental. Nesse sentido, destaca-se nos estudos da resiliência regional a referência aos "sistemas sócio-ecológicos" (SSE). O The Resilience Alliance (2007) define sistemas socioecológicos como o conjunto formado pelos ecossistemas e a sociedade humana, com as suas interações e interdependências entre os componentes ecológicos, sociais, econômicos, culturais e tecnológicos. Exemplos claros deste esforço analítico podem ser vistos em trabalhos como o de Bristow (2010), Simmie e Martin (2010) e Pike et al. (2010), dentre outros. Esses pesquisadores têm buscado na literatura sobre SSE elementos para avançar nas discussões referentes a esta passagem conceitual para o âmbito do desenvolvimento regional.

Entretanto, tal esforço ainda deixa muitas dúvidas sobre sua validade teórica e, evidentemente, não é consensual. Para Simmie e Martin (2010), um dos principais problemas está no que eles chamam de pensamento equilibrista. Este olhar está sustentado na "resiliência da engenharia", a qual se concentra na estabilidade de um sistema perto de um equilíbrio ou estado estacionário, em que a resistência à perturbação e a velocidade de retorno para o equilíbrio pré-existente são usadas para determinar a resiliência. Isso parece mais próximo da noção de "elasticidade", ou da capacidade de um sistema para absorver e acomodar perturbação sem experimentar transformação estrutural maior ou colapso. A implicação deste pensamento é que quanto mais resiliente é uma economia regional, menos irá mudar ao longo do tempo, mesmo em face de diversos choques. Assim, na melhor das hipóteses, essa visão renderia um modelo evolutivo baseado na manutenção da estrutura e da estabilidade regional (SIMMIE \& MARTIN, 2010). Portanto, uma região resiliente não necessariamente mudaria ao longo de tempo, o que contrasta com o dinamismo percebido nas economias regionais bem sucedidas.

Para superar esses limites, Simmie e Martin (2010) e Pike et al. (2010) discutem a possibilidade de um sistema ter múltiplos equilíbrios, entendendo que as condições de distúrbios (perturbações) poderiam mudar o sistema de um ponto de equilíbrio para outro.É uma ideia simpática à economia clássica, para quem não há estado de equilíbrio único, mas vários estados possíveis ou caminhos aos quais uma economia 
pode ser deslocada em função de um choque ou perturbação (SIMMIE e MARTIN, 2010). Esta concepção enfoca o papel que choques ou perturbações exercem ao empurrar um sistema para além do seu "limite de elasticidade", ou seja, para um novo domínio (MARTIN, 2012).

A noção de resiliência presente no "pensamento equilibrista" também é discutida por Christopherson et al. (2010), que veem com preocupação a ideia de um caminho de equilíbrio único. Pensam ser um pouco mais realista a ideia de múltiplos equilíbrios, segundo a qual, se o caminho de crescimento anterior desaparecer por qualquer motivo, pode haver um ou mais caminhos alternativos para o desenvolvimento da região. Entretanto, ainda segundo esses autores, por mais que o modelo de múltiplos equilíbrios possa ser útil para fins de modelagem, seria improvável que o mesmo desse conta de representar toda a complexidade dos sistemas regionais estudados.

Hassink (2010) é ainda mais rigoroso ao afirmar que a ideia de múltiplos equilíbrios não é suficiente para explicar a evolução das economias regionais, e, portanto, seria insuficiente para determinar a resiliência de uma região. Esse olhar também é compartilhado por Pendall et al. (2009), os quais chamam atenção para o fato de que muitos dos estudos de resiliência, em especial nos Estados Unidos, têm no modelo de equilíbrios múltiplos a principal fonte de inspiração. Tais estudos, normalmente, procuram apontar se a região é mais ou menos resiliente e não avançam no entendimento do processo que leva a esta resiliência.

Já Cowell (2013), além de concordar com Pendall et al. (2009) e Hassink (2010), argumenta que o pensamento equilibrista não discute as vantagens e as desvantagens de se retomar o estado de desenvolvimento anterior à perturbação ou de se ajustar a um novo equilíbrio. Além disso, não aborda como os atores regionais passam a se preparar para lidar com problemas futuros ou como podem aprender com os erros do passado e responder a um novo desafio.

De fato, o limite para a construção do conceito de resiliência na teoria do desenvolvimento regional parece estar, justamente, na sua origem funcionalista: a suposição de um ponto ótimo de equilíbrio, inspirado nas ciências naturais e, o mais grave (do ponto de vista da geografia econômica), atrelado aos fundamentos da economia neoclássica, sendo incapaz de explicar a dinâmica real das regiões. Atenta a este limite, parte da literatura vem amadurecendo no sentido de "liberar" a resiliência da ideia de equilíbrio e, em contrapartida, associá-la à capacidade de adaptação. Para autores como Hudson (2009), Pendall et al. (2009), Christopherson et al. (2010), Dawley et al. (2010), Pike et al. (2010), Simmie e Martin (2010), Santos (2009a), entre outros, a ligação de resiliência com a ideia de adaptabilidade é muito mais rica e promissora para entender como as regiões respondem às perturbações e às crises ao logo de suas trajetórias de desenvolvimento. Esta nova linha de pensamento vem resultando na construção de uma noção evolutiva em que a resiliência de uma região passa a ser percebida como um processo, não estando atrelada a equilíbrios únicos ou múltiplos, mas sim a um "sistema adaptativo 
complexo" (SIMMIE \& MARTIN, 2010). Este olhar também é compartilhado por Walker et al. (2002), Walker et al. (2004), Walker et al. (2009), Santos (2009b) e Folke et al. (2010).

Nessa visão, a resiliência não deve ser entendida como um ativo fixo, mas como um processo em constante mudança (DAVOUDI, 2012). Compreender a resiliência como um processo destaca a necessidade de compreender feedbacks, ou seja, as estruturas cognitivas, institucionais e materiais que dificultam ou permitem a mudança (DARNHOFER, 2014). Este autor também destaca que a resiliência é ativa e criativamente realizada quando um sistema é confrontado com distúrbios e stress, não podendo, portanto, ser reduzida a uma resposta "automática" que deriva diretamente das propriedades do sistema. Em vez disso, a resiliência depende de aprendizagem contínua para que se façam melhores escolhas e para melhorar a capacidade de lidar com a mudança.

Portanto, a noção de resiliência regional admitida atualmente como a mais promissora pela bibliografia especializada é aquela associada a um processo de ajustamento contínuo, o qual depende da capacidade de adaptação do sistema em face às grandes tendências evolutivas de cunho econômico, social, ambiental, político e tecnológico que impactam as regiões. Nesta vertente, um sistema resiliente seria um sistema adaptativo, que ajusta e responde sem danificar ou comprometer o seu funcionamento eficaz, mantendo a sua trajetória de desenvolvimento ou fazendo a transição para o novo.

\section{Perturbação, crise, transformação e gestão}

Segundo Santos (2009b), para se compreender como ocorre o processo de adaptação em uma região é importante, também, se separar a noção de perturbação e de crise, além de explorar ideias ligadas à transformação e gestão da resiliência. Para tanto, partimos do princípio de que a resiliência percebida como um processo ajuda a explicar como as regiões se ajustam e respondem a choques, de maneira a manter sua trajetória de desenvolvimento ou, em último caso, se transformam, fazendo a transição para algo novo. A criação de resiliência regional, nesta perspectiva, seria mais propriamente considerada como uma aprendizagem social (empresas, comunidade, poder público e suas relações), usando as capacidades humanas e o conhecimento para reduzir a vulnerabilidade e o risco em face do desconhecido e do inesperado.

Folke et al. (2010) põem ênfase na suposição de que a dinâmica existente entre períodos de mudanças graduais (perturbações) e bruscas (crises) revela a capacidade não só de adaptação, mas também de transformação do SSE. Enquanto a primeira pode ser definida como um acontecimento relativamente discreto no tempo, geralmente proveniente do exterior, provocador de rupturas e mudanças na região e que ainda pode criar novas condições e oportunidades; a segunda é mais dramática. 
Uma crise é um período de intensa dificuldade e perigo que, com o tempo, força a tomada de decisões importantes, sendo mais persistente que a anterior. Assim, as crises podem também ser uma oportunidade de reconstruir uma região através de um novo elemento: a transformação. Portanto, uma região resiliente, além de promover ajuste na sua trajetória de desenvolvimento através da adaptação, pode também se transformar, à medida que seja obrigada a enfrentar desafios, por exemplo, de reconversão produtiva. Nesta situação, uma crise pode desencadear novas soluções e respostas, permitindo a adoção de uma nova trajetória de desenvolvimento.

A incorporação do processo de transformação no debate sobre a resiliência regional tem aumentado a aplicação deste conceito em estudos sobre o desenvolvimento regional. Tanto que, ao se recorrer ao conceito de resiliência regional mais comumente usado pela bibliografia especializada, percebe-se que, por mais que o mesmo permita diferentes interpretações - conforme argumentam Santos (2009a) e Hudson (2009) -, há uma clara valorização dos aspectos ligados não só à adaptação, mas também à transformação, vide os trabalhos de Pendall et al. (2009), Pike et al. (2010) e Simmie e Martin (2010).

No entanto, a dificuldade analítica para se acolher a "transformação" como um segundo processo para explicar a resiliência regional estaria no seu próprio significado. Mais desafiadora que a adaptação, a transformação indicaria uma ruptura dramática no trajeto, em que as circunstâncias geradas levariam a uma impossibilidade de se flexibilizar as estratégias dos agentes. Nesse sentido, a transformação seria a própria negação da resiliência, ou um processo que expressaria os limites das forças produtivas próprias de uma região frente a um contexto de crise. Essa é uma questão que, em princípio, ainda não foi devidamente visitada pela literatura.

Outro elemento apontado na discussão da resiliência regional diz respeito à gestão da resiliência. Lebel et al. (2006) chamaram a atenção para o fato de que a capacidade de mantê-la residiria nos atores, nas redes e nas instituições, sendo de grande valia para a obtenção de um desenvolvimento regional "mais seguro". Santos (2009a), posteriormente, enfatizou que gerir a resiliência é fundamental para evitar que o SSE se mova para configurações indesejáveis. Para tanto, seria necessário compreender como cada sistema conquista sua resiliência e como ela pode ser perdida. Acrescenta, ainda, que seria importante identificar pontos de intervenção que permitam aumentar a capacidade de adaptação. Com este enfoque, poder-se-ia afirmar que a resiliência se traduz, na dinâmica regional, como a capacidade de ser flexível, social, ecológica e economicamente. Estaria implícito no conceito o reconhecimento de que os SSE e os seus contextos mudam continuamente, e que a resiliência confere a capacidade de adaptação, de aprendizagem e de reestruturação contínua.

Para Foster (2007), Hudson (2009) e Pike et al. (2010), também as autoridades governamentais têm um papel fundamental na gestão da resiliência regional através do envolvimento dos diferentes atores no planejamento regional, o que possibilitaria 
a aprendizagem social. Este olhar procura marcar distância com possíveis filiações às teses do livre mercado e também é compartilhado por Foster (2007) e Ficenec (2010), para quem a resiliência depende em parte da capacidade das autoridades políticas para assegurar o planejamento eficaz e a implantação de estratégias em resposta às perturbações do sistema.

De qualquer modo, nos estudos, em geral, ainda permanece forte a suposição de que a resiliência é um processo gestado dentro ou para o "sistema socioecológico", cuja definição é muito ampla, difusa e pouco comum em estudos sobre a economia regional. Da mesma forma que a literatura está procedendo a "passagem" do conceito das ciências ecológicas (calcada em um pensamento equilibrista) para as ciências sociais e econômicas (apoiada na ideia de capacidade adaptativa), outra fronteira do debate poderia - ou deveria - estar no uso mais apropriado ou preciso da noção de sistema (aplicado a estudos regionais) e de como este poderia acolher a resiliência num marco teórico que analise o comportamento evolutivo da região frente ao cenário econômico e seus ciclos.

\section{Desafios metodológicos}

As noções de resiliência predominantes na literatura que trata do desenvolvimento regional ainda se mostram amplas e difusas, demandando maior exploração e aprofundamento. $\mathrm{O}$ mesmo ocorre devido ao fato de encontrar-se em pleno processo de lapidação e consolidação, em que a literatura disponível evidencia diferentes usos para o termo, muitas vezes com significados bem distintos (MÉNDEZ, 2012). Conforme lembra Darnhofer (2014), medir a resiliência de uma região tem se mostrado "como mirar em um alvo em movimento". A elaboração de estudos sobre a resiliência regional enfrenta, ainda, graves desafios metodológicos, como a definição de espaço (limites regionais em que a resiliência pode ser observada e medida) e a definição da escala de tempo. Nesse sentido, Pendall et al. (2009) alertam para a complexidade desse desafio. Também há que se considerar a delimitação do espaço de estudo por parte do pesquisador, o mesmo pode tornar uma região mais ou menos resiliente simplesmente manipulando as fronteiras regionais para abranger ou eliminar territórios, sendo que isso também se aplica para o tempo.

Além da demarcação dos limites geográficos e do tempo, precisa-se, também, reconhecer se o que a região enfrenta é o que Pike et al. (2010) chamam de choques agudos (eventos abruptos) ou distúrbios crônicos (queimaduras lentas). O primeiro remete a um evento repentino de grandes proporções, já o segundo caracteriza eventos lentos de longa duração. Enquanto alguns anos podem ser o suficiente para entender a resiliência de uma região devido a um choque agudo, como um terremoto, por exemplo, em outros casos pode-se levar uma geração para perceber como aquela região está mudando em virtude de distúrbios crônicos, como ocorre 
com a transformação econômica prolongada. Choques agudos tendem a ser mais facilmente identificáveis nas análises de resiliência, principalmente os originados por desastres naturais, e por isso são relativamente bem estudados. Já os eventos de distúrbios crônicos, ao contrário, normalmente são mais difíceis de identificar e, consequentemente, ainda pouco estudados, embora ambos sejam fundamentais para determinar a resiliência de uma região.

Nesse sentido, Christopherson et al. (2010) sugerem que um dos caminhos para explicar a resiliência pode se dar pela análise de diferentes regiões ao logo do tempo e, para tanto, argumentam que se deve atentar para alguns elementos: a presença de um sistema regional de inovação; a identificação de fatores que criam uma região de aprendizagem; a infraestrutura produtiva (transportes, acesso à banda larga etc.); a força de trabalho capacitada a inovar e a empreender; um sistema de apoio financeiro; e uma base econômica diversificada não dependente de um único setor.

Já Bristow (2010) aponta características consideradas importantes para sustentar a resiliência regional, tais como: diversidade de empresas, de instituições e de meios de ganhar a vida; políticas de valorização das atividades que estão embutidas nas capacidades do meio ambiente local e adaptadas aos seus limites; e, finalmente, em virtude da necessidade de utilização mútua dos ativos locais, a resiliência implica, também, em uma economia de apoio à família, à comunidade e à sociedade civil.

Hopkins (2008) acrescenta que as regiões podem variar sua capacidade de adaptar-se e responder a eventos negativos ao longo do tempo. Estariam expostas, assim, a diferentes graus de resiliência. As estratégias de desenvolvimento regional adotadas teriam, portanto, grande importância para o incremento ou a erosão da resiliência existente.

Para Hudson (2009), as políticas neoliberais são as principais responsáveis pela erosão da resiliência e pela criação de regiões mais propensas a sofrer danos perante as perturbações ou crises (SANTOS, 2009b). Nesse sentido, a resiliência regional não seria um atributo estático, mas sim uma construção complexa que pode ajudar a explicar por que determinadas regiões prosperam enquanto outras encontram mais dificuldades. Desta forma, a promoção da resiliência ajudaria a garantir uma transição bem conduzida para uma economia regional mais sustentável e socialmente justa.

Evidentemente, isso não significa que a resiliência esteja livre de questionamentos e seja a panacéia para todos os pontos obscuros de desenvolvimento regional. Tanto que Walker et al. (2002) afirmam que a resiliência não é necessariamente desejável; afinal, podem existir configurações de sistemas, como uma ditadura, que reduzem o bem-estar social, mas que podem ser altamente resistentes à mudança. Como tal, não ofereceria uma solução definitiva para a escolha dos atributos que as regiões precisariam desenvolver para lidar com as vulnerabilidades, em um mundo incerto.

Já Hassink (2010) se mostra muito cauteloso, alertando que é necessário analisar cuidadosamente o valor da resiliência para entender a adaptabilidade das economias 
regionais, em especial por se tratar de um "conceito da moda". O autor ainda lembra que abraçar a ideia de resiliência muito rapidamente poderia conduzir a uma repetição de erros, muitas vezes feita no passado, tanto na geografia humana, como na geografia econômica.

O tema, porém, continua ganhando interesse e até mesmo o entusiasmo de vários autores. Para Pike et al. (2010), a utilidade deste conceito continua sendo contestada, em parte, devido a dificuldades na definição e operacionalização, mas também porque alguns pesquisadores veem como menos útil do que outros conceitos existentes. Para este autor, ele abre novas perspectivas no pensamento sobre desenvolvimento regional, o que aponta para a necessidade de avançar nas discussões e no estudo da mesma.

Christopherson et al. (2010) afirmam que há muitas evidências nos estudos até então desenvolvidos que permitem afirmar que a resiliência tem muito a colaborar para o entendimento das dinâmicas por trás das mudanças regionais. Bristow (2010) chega a argumentar que a resiliência tem a capacidade de exibir "propagação viral" e consegue cortar toda a chamada "zona cinzenta" entre acadêmica, política e o discurso prático.

O certo é que o conceito ainda está em construção e que os estudos empíricos ainda terão muito a oferecer para a superação dos desafios metodológicos. Hudson (2009), por exemplo, reconhece que a análise da resiliência ainda está evoluindo e que há faltas e fraquezas na conceituação científica.

Em última instância, os avanços empíricos poderiam impactar na revisão de estratégias de desenvolvimento regional que estão condicionadas exclusivamente às metas de aumento da competitividade das empresas e dos territórios. Em outras palavras, poder-se-ia ampliar o leque de ações da política regional para além da criação de estímulos a uma produtividade superior, ou da atração de novas empresas para incrementar a capacidade competitiva da região. Sem desmerecer as vantagens competitivas, a ênfase na resiliência aposta na importância para a dinâmica regional dos fatores que conferem adaptabilidade a novos cenários econômicos e favorecem respostas rápidas a contextos de crise e perturbação.

\section{Mapeamento da literatura que trata da resiliência no desenvolvimento regional}

A opção por realizar um mapeamento da literatura se dá em função das possíveis contribuições deste esforço para o andamento do trabalho em questão. Afinal, essa técnica fornece um apanhado das principais publicações sobre o tema. Com isso, este monitoramento auxiliará na extensão do olhar sobre o que é produzido a respeito do tema da resiliência regional.

Um mapeamento da literatura pode ser definido como a construção de um portfólio de publicações relativas a um determinado tema, que é segmentado segundo os focos de pesquisa de cada uma das publicações. Sendo que, o mesmo 
acontece em três etapas: coleta de dados, análise bibliométrica e mapeamento.

\section{Coleta de Dados}

Nesta primeira etapa, partiu-se da literatura apresentada anteriormente, na qual foram escolhidos os termos de busca da pesquisa: Regional resilience ou Resilient regions. Essa opção foi feita para delimitar a busca, sendo que foram estes os termos que se mostraram mais representativos para o estudo da resiliência no âmbito do desenvolvimento regional. A opção por usar os termos de pesquisa na língua inglesa é justificada pelo fato de que quase a totalidade das publicações a respeito da resiliência regional se encontra neste idioma, conforme já demonstrou Janssen (2007). Outro fator importante foi o período de busca. Como a coleta de dados se deu entre os dias 03 e 08 de fevereiro de 2014, decidiu-se por limitar a busca a todo o período anterior a 31 de dezembro de 2013, possibilitando, assim, a melhor caracterização deste fenômeno como algo recente nos estudos sobre o desenvolvimento regional. Já quanto às bases de dados, optou-se por utilizar três fontes tradicionais de pesquisas científicas que apresentam relevante acervo na área das Ciências Sociais: (1) Scopus, (2) EBSCO host, e (3) Web of Knowledge. Em todas as bases, optou-se por pesquisar os termos de busca no título (title), no resumo (abstract) e nas palavras-chave (Key Words) de documentos no formato de artigo (jornal article). Com isso, foram obtidos noventa e sete resultados, sendo setenta e nove para o termo Regional resilience e dezoito para Resilient regions, com os quais se realizou a análise bibliométrica. É importante, ainda, frisar que os termos de busca escolhidos, juntamente com os locais de procura por estes termos (título, resumo e palavras chaves), somado ao formato definido para os documentos (apenas artigos em revistas), foram bem restritivos, limitando o número de artigos encontrados. Isso se justifica pela necessidade de encontrar o conjunto de publicações mais específicas e relevantes sobre o tema. Tal estratégia também permite que, a partir da análise detalhada das publicações-chave encontradas, sejam localizadas outras contribuições importantes que eventualmente não foram identificadas inicialmente.

\section{Análise Bibliométrica}

A análise bibliométrica permite realizar um profundo detalhamento dos dados, possibilitando verificar, dentre outras informações, quais autores e periódicos mais contribuem para o estudo do tema, bem como os locais e anos de maior publicação. Para tanto, inicia-se com o resumo da quantidade de resultados obtidos em cada base de dados pesquisada, o qual se encontra na Figura 1. 


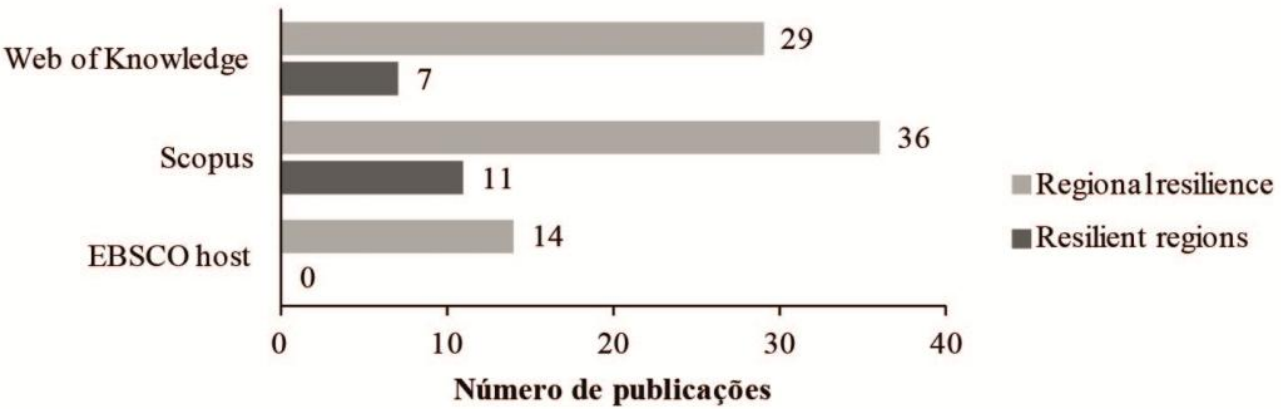

Figura 1: Número de artigos encontrados nas bases de dados para os dois termos de pesquisa (Regional resilience e Resilient regions).

Como esperado, o termo de pesquisa Regional resilience permitiu encontrar um número maior de trabalhos, já que este termo é mais comumente usado nos trabalhos sobre desenvolvimento regional. Já o termo Resilient regions, embora seja menos utilizado, também foi útil por permitir localizar alguns outros trabalhos importantes. Em relação às bases de dados, destaca-se a base Scopus por apresentar o maior número de contribuições, sendo que muitos dos artigos encontrados nas outras bases também estavam presentes na Scopus. Portanto, foi necessário que os resultados obtidos nas três bases fossem submetidos a um processo de filtragem para a identificação e eliminação dos arquivos em duplicata. Para executar esta tarefa foi utilizado o programa EndNote ${ }^{\circledR}$. Através desse programa, foi constatada a presença de cinquenta duplicatas, restando, então, um total de quarenta e sete documentos, distribuídos em trinta e cinco "journal" distintos. Destes periódicos, apenas quatro apresentaram mais de uma publicação, conforme pode observar-se na Figura 2. 


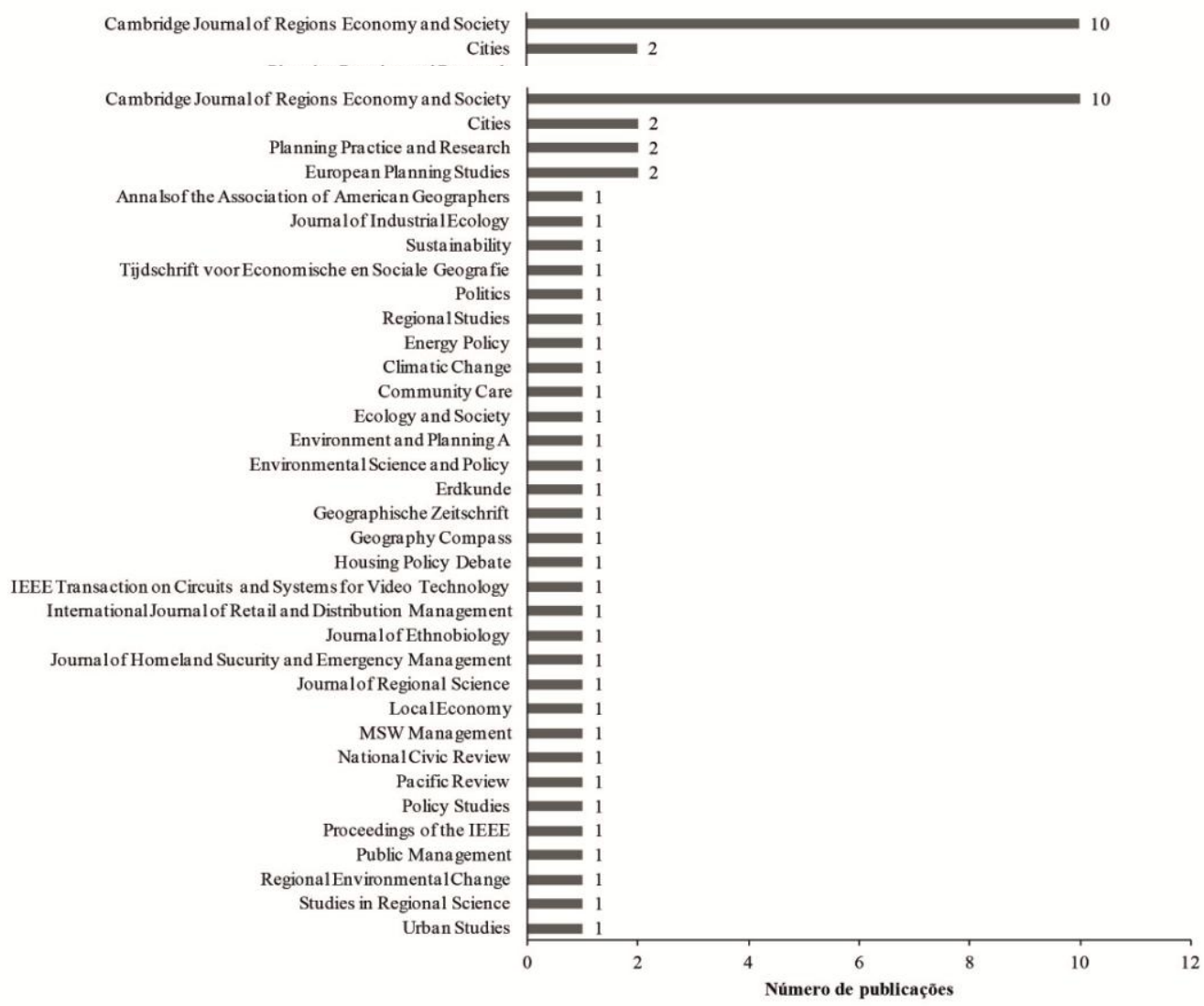

Figura 2: Periódicos onde foram publicados os artigos encontrados nesta pesquisa.

Os resultados presentes na Figura 2 demonstram que existe uma enorme distribuição das publicações em um grande número de revistas. Exceção feita à revista inglesa Cambridge Journal of Regions Economy and Society, que apresentou dez publicações. O maior destaque desta revista se deve, principalmente, pela publicação de uma edição especial (número 3, de 2010) dedicada a explorar diferentes olhares a respeito da resiliência regional. Segundo o corpo editorial da mesma, a opção por publicar uma edição especial sobre a resiliência regional justifica-se pela popularidade que o termo alcançou, principalmente nos Estados Unidos e Inglaterra, e pela necessidade de avançar no entendimento das contribuições do mesmo para o estudo do processo de desenvolvimento das regiões.

O maior interesse pelo tema nos Estados Unidos e na Inglaterra pode ser comprovado pela Figura 3. Estes dados corroboram com o trabalho de Janssen (2007), que também observou o predomínio de publicações sobre resiliência (neste caso, de um modo mais geral, para diferentes áreas) nestes países. É importante 
frisar que a figura em questão apresenta apenas os países onde foram encontrados mais de um periódico com publicação sobre o tema em pelo menos uma das bases de pesquisa.

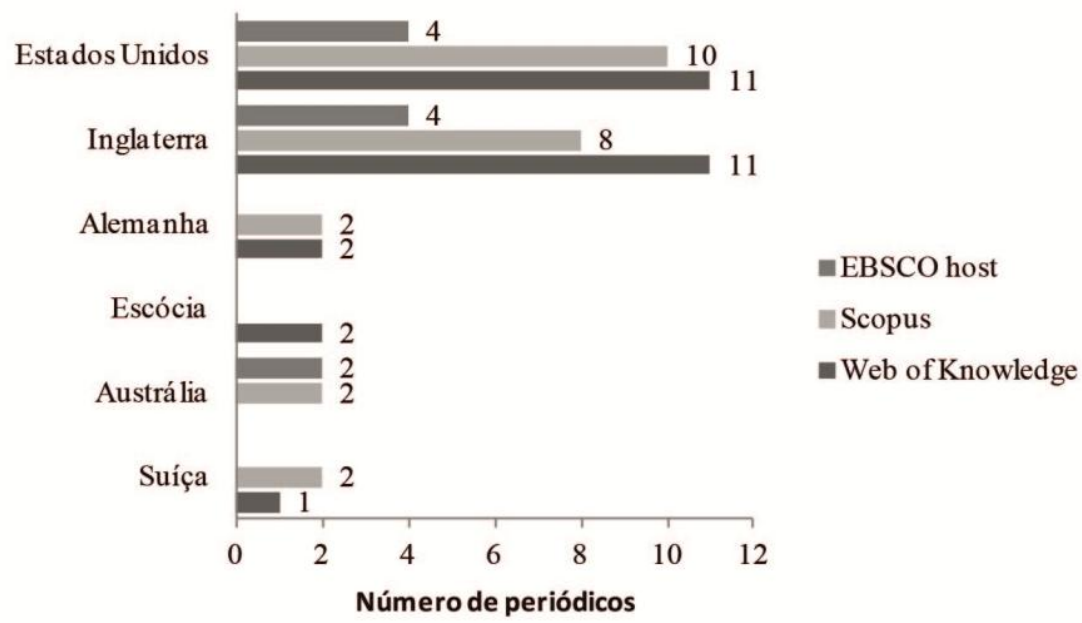

Figura 3: Países com maior predomínio de periódicos com publicações para os diferentes termos de busca, nas três bases de pesquisa analisadas.

O predomínio de revistas americanas e inglesas nas publicações sobre este tema acaba também criando um efeito atrativo para trabalhos sobre resiliência regional que foram realizados em outras partes do mundo. Como conseqüência, as revistas destes países tendem a concentrar as publicações mais relevantes sobre o tema. Outro fator que chama atenção é a distribuição das publicações ao longo do tempo, bem como a relação das mais relevantes para trabalhos focados no desenvolvimento regional (Figura 4).

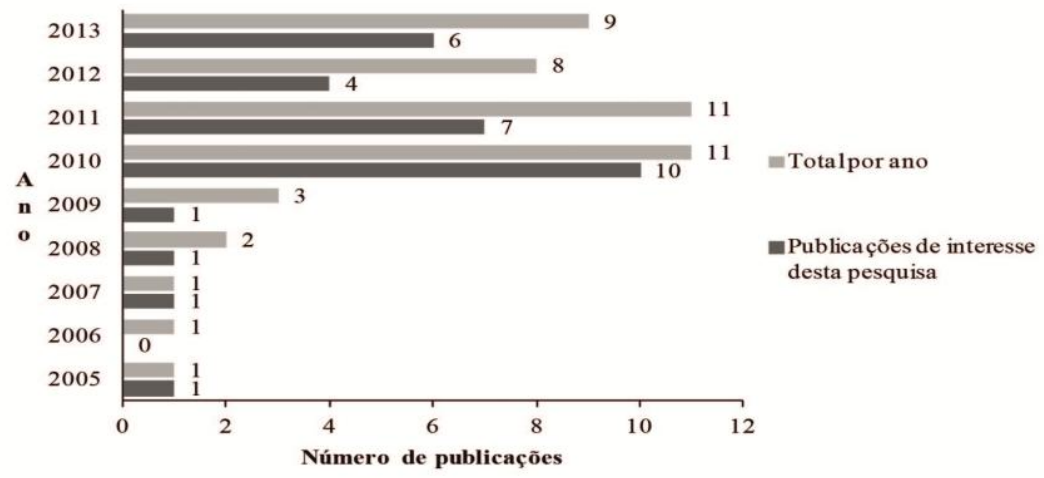

Figura 4: Número de artigos encontrados por ano de publicação comparado com o número de artigos de maior interesse para esta pesquisa. 
Ao analisar a Figura 4, fica evidente que o tema da resiliência regional começou a aparecer nos trabalhos só recentemente, no ano de 2005. Isso mostra o ineditismo do tema quando o assunto é desenvolvimento regional, e, ao mesmo tempo, se configura numa abordagem teórica em pleno processo de construção, em que muito ainda se tem a avançar. A informação anterior também ajuda a explicar duas outras situações. A primeira remete ao fato de não haver publicações sobre resiliência regional anteriores a 2005. Na verdade, é possível encontrar algumas poucas publicações anteriores a esta data. Contudo, elas não adotaram os termos de busca aqui usados (Regional resilience e Resilientregions), pois tais termos passaram a se consolidar só mais recentemente. Embora este fato não seja uma exclusividade do passado, ainda se encontra trabalhos que tratam da resiliência regional, mas que não adotam este termo; usam, por exemplo, apenas resiliência. Obviamente que nesses casos é mais difícil de localizar os trabalhos, já que os mesmos ficam misturados com outras abordagens de resiliência, como desastres naturais, aquecimento global, psicologia, dentre outros. Já a segunda, refere-se justamente ao oposto, trabalhos que têm, por exemplo, foco na resiliência em desastres naturais, mas que usam o termo resiliência regional em algum tópico específico e que pouco tem a contribuir com este tema. Esse tipo de situação também se encontra representado na Figura 4, na qual em cinza claro está o total de publicações por ano e em cinza escuro estão as de interesse desta pesquisa. Essa situação pode ser mais bem compreendida ao se analisar a Figura 5.

A Figura 5 apresenta os quarenta e sete artigos obtidos nesta pesquisa, distribuídos em diferentes domínios. Os domínios usados foram adaptados dos propostos por Santos (2011), acrescidos de um novo, a saber, Povos tradicionais $e$ meio ambiente. Para classificar cada artigo em um domínio, foi realizada a leitura do título e do resumo, e, em casos que ainda se suscitava dúvida, a leitura foi estendida também ao restante do artigo.

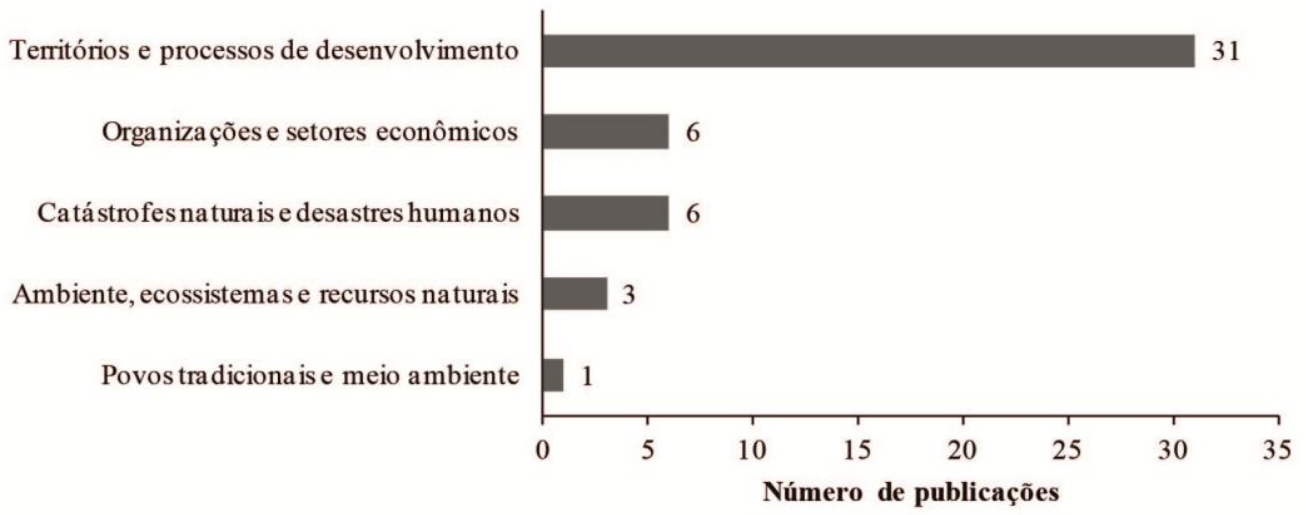

Figura 5: Distribuição dos documentos encontrados em diferentes domínios, em função do foco de pesquisa. 
É importante frisar que os cinco (5) domínios usados neste trabalho para agrupar os diferentes artigos se inter-relacionam e não são estanques. Todos os artigos abordam o tema da resiliência regional, no entanto, somente trinta e um têm como abordagem central o processo de desenvolvimento das regiões a partir do olhar da resiliência. Portanto, são tais artigos os de maior interesse para este trabalho, os quais foram mais minuciosamente estudados.

A análise detalhada dos artigos do grupo territórios e processo de desenvolvimento poderia, entre outras coisas, revelar os pesquisadores que são referências no tema. Assim, primeiramente apenas foram observados os autores com maior número de publicação. Entretanto, todos os artigos tinham autores e coautores diferentes, a mesma situação se repetiu quando a análise foi ampliada, incluindo todos os domínios. Aparentemente, dois fatores corroboram para este resultado, o primeiro e mais importante é o ineditismo do tema, que reduz a possibilidade de existirem muitos autores de referência. Já o segundo pode estar associado ao caráter restritivo desta pesquisa, que limitou o número de trabalhos encontrados no sistema de busca.

Evidentemente que a localização dos autores que são referência para o tema pode ser dada de outras formas, como na análise detalhada dos artigos encontrados, em que se observam as principais citações que sustentam os trabalhos. Ou ainda, recorrendo à base de dados na qual é possível identificar os artigos e, consequentemente, os autores com maior número de citações (Tabela 1). Esta informação é importante porque atrela o número de citação do autor a um trabalho específico, e não à produção geral deste autor, que pode conter trabalhos sobre diversos temas. 


\begin{tabular}{ccc}
\hline Referências & Revistas & $\begin{array}{c}\mathbf{N}^{\mathbf{0}} \mathbf{\text { de }} \\
\text { citações }\end{array}$ \\
\hline $\begin{array}{c}\text { Walker, et al. } \\
(2009)\end{array}$ & Ecologus & 36 \\
\hline $\begin{array}{c}\text { Simmie e Martin } \\
(2010)\end{array}$ & Cambridge Journal of Regiões, Economia e Sociedade & 35 \\
\hline Hudson (2010) & Cambridge Journal of Regiões, Economia e Sociedade & 21 \\
\hline Hassink (2010) & Cambridge Journal of Regiões, Economia e Sociedade & 15 \\
& Web of Knowledge & \\
\hline
\end{tabular}
Simmie e Martin (2010)

Walker, et al. (2009)

Hassink (2010) Cambridge Journal of Regiões, Economia e Sociedade 13

Hudson (2010) Cambridge Journal of Regiões, Economia e Sociedade 10

Tabela 1: Artigos sobre o tema resiliência regional disponíveis nas bases de dados Scopus e Web of Knowledge, ordenados em função do número de vezes que são citados em outros trabalhos.

Na Tabela 1, os artigos encontrados na base EBSCO host não se encontram ordenados pelo número de vezes que são citados. Isso ocorreu porque esta base não disponibiliza a ferramenta que permite o acesso a tal informação. No entanto, esse fato não compromete o trabalho, já que foram encontrados apenas 14 artigos nesta base, dos quais apenas quatro não estavam disponíveis em uma das outras bases consultadas, e, ainda, nenhum desses quatro foi agrupado no domínio de interesse desta pesquisa (territórios e processo de desenvolvimento). Por fim, é fundamental destacar a influência que principalmente os trabalhos de Walker, et al. (2009) e Simmie e Martin (2010) têm nos estudos sobre a resiliência regional. Uma discussão mais aprofundada sobre esta informação, bem como sobre outras informações presentes nesta análise bibliométrica, encontram-se na etapa de mapeamento que segue. 


\section{Mapeamento}

Nesta etapa, procura-se analisar mais detalhadamente os resultados obtidos na análise bibliométrica. O primeiro destaque fica por conta dos termos usados para busca nas bases de dados, em que, conforme sinalizavam as leituras prévias, o termo Regional resilience configura-se como o mais promissor quando se trata do estudo do processo de desenvolvimento das regiões. Este termo é especialmente utilizado por pesquisadores da geografia econômica, mas também começa a ganhar espaço em outros importantes grupos, como os pesquisadores da vertente socioecológica (SSE). Outro fator importante é que a maioria dos trabalhos sobre a resiliência regional busca elementos teóricos em alguns importantes autores socioecológicos (SSE), como pode ser visto ao longo deste trabalho. Além disso, também autores desta corrente, como Walker, et al. (2009), trabalhos mais vezes citados conforme observado na análise bibliométrica, têm realizado importantes estudos sobre o tema da resiliência regional. Pode estar sendo aquecido, aqui, um debate necessário sobre a conveniência teórica e a possibilidade de aproveitamento da noção de SSE - ou dos elementos que contempla - nos estudos sobre o papel da resiliência no desenvolvimento regional.

Mas a análise bibliométrica permitiu, sobretudo, identificar dentre os artigos encontrados sobre o tema estudado os de maior relevância, isso mediante o número de vezes que cada artigo é citado. Claro que essa informação é um recorte no tempo, e como tal é mutável, afinal, podemos ter um artigo mais recente de grande qualidade, mas que ainda não atingiu um número grande de citações, justamente pelo tempo que está disponível para acesso de outros pesquisadores. Sendo assim, optou-se por realizar uma análise detalhada das referências bibliográficas que dão suporte aos artigos do grupo territórios e processo de desenvolvimento. Nesta análise, se destacam os autores já identificados na análise bibliométrica - B. H. Walker, J. Simmie, R. Hassink, R. Hudson e R. L. Martin - , além de outros como: K. A. Foster, M. M. Cowell, R. Pendall e A. Pike. Também chama atenção o expressivo número de vezes que os pesquisadores C. S. Holling e C. Folke são citados nos trabalhos desse estudo. Isso não surpreende, visto que Janssen (2007) identificou que C. Folke, da Universidade de Estocolmo, lidera com o maior número de publicações sobre resiliência. Já Holling, atualmente professor emérito da Universidade da Flórida, é de longe o autor mais citado. Estes pesquisadores tem contribuições que podem ser úteis para diferentes abordagens de resiliência, como é o caso da resiliência regional.

Por fim, as contribuições da análise bibliométrica permitiram o enriquecimento e a qualificação da revisão bibliográfica referente à resiliência regional. Esta técnica permite um navegar mais seguro mesmo em águas turbulentas resultantes da construção de uma nova abordagem conceitual. 


\section{Considerações Finais}

Este trabalho procurou, com o apoio da bibliografia disponível, apresentar a origem, evolução e os avanços que o conceito de resiliência sofreu nos últimos anos. Além disso, foi possível identificar o crescente interesse pelo tema, a legitimidade e a importância que o mesmo vem conquistando tanto no meio acadêmico como nas políticas públicas ligadas ao planejamento territorial. Os estudos mapeados são reveladores de que o pensamento equilibrista serviu ou está servindo como um "meio de passagem" da noção de resiliência das ciências ecológicas para o campo do desenvolvimento regional. No entanto, a premissa do equilíbrio, devido ao seu caráter funcionalista, não resiste ao aprofundamento da análise econômica e vem sendo substituída, por parte da literatura, pela ideia de capacidade adaptativa, muito mais profícua para o estudo da dinâmica regional. As regiões resilientes seriam, portanto, aquelas melhor adaptadas à mudança, menos vulneráveis à turbulência e aos choques externos e com respostas mais rápidas para evitar colapsos socioeconômicos.

Ainda assim, o uso do conceito de resiliência pela Geografia - em particular, a Geografia econômica - é muito recente e possui importantes flancos teóricos e metodológicos para responder às inquietudes dos estudos sociais e econômicos. Entendê-lo como um atributo histórico e geograficamente construído é o desafio essencial que se apresenta à literatura para superar os seus limites.

As diferenças entre adaptação e transformação, por exemplo, são ainda obscuras e levam ao questionamento sobre quando e sob que condições a resiliência é capaz de explicar as respostas da região em períodos de crise. Outro limite é o uso de matrizes analíticas apoiadas no SSE, cuja adequação para tratar da evolução da economia regional é no mínimo duvidosa. Em termos metodológicos, permanecem as perguntas sobre a escala da resiliência e o papel do Estado, das instituições e da política pública na sua construção. Certamente, a teoria não pode avançar solidamente sobre essas questões sem a contribuição indispensável dos estudos empíricos.

Finalmente, explorar a noção de resiliência regional como um conceito traz como consequência teórica a valorização da geografia econômica como âmbito do debate sobre o desenvolvimento. Os estudos sobre resiliência contêm uma perspectiva promissora para pensar e planejar o futuro das regiões, trazendo o foco à preocupação com a menor vulnerabilidade, a melhor resposta a contextos de crise, à diversificação das estratégias e à redução dos efeitos negativos das crises setoriais. Este conceito pode ser muito útil por considerar questões que vão além do aumento do desempenho competitivo e da especialização territorial, e por ser capaz de lidar com as capacidades adaptativas e suas vantagens, embora ainda careça de maior reflexão e aprofundamento dos estudos empíricos. 


\section{Bibliografia}

ALEXANDER, D. (2013) Resilience and disaster risk reduction: an etymological journey. Natural Hazards and Earth System Sciences, v.13. pp. 2707-2716.

ASHBY, J., et al. (2009) Delivering economic success: An international perspective on local government as stewards of local economic resilience. Manchester, Report by the Centre for Local Economic Strategies, $126 \mathrm{p}$.

BRANDÃO, J. M.; MAHFOUD, M.; GIANORDOLI-NASCIMENTO, I. F. (2011) A construção do conceito de resiliência em psicologia: discutindo as origens. Paidéia, v. 21, n 49. pp. 263-271.

BRISTOW, G. (2010) Resilient regions: re-'place'ing regional competitiveness. Journal of Regions, Economy and Society, Cambridge, v. 3. pp. 153-167.

CHRISTOPHERSON, S.; MICHIEB, J.; TYLERC, P. (2010) Regional resilience: theoretical and empirical Perspectives. Cambridge Journal of Regions, Economy and Society, Cambridge, v. 3. pp. 3-10.

COAFFEE, J.; MURKAMI-WOOD, D.; RODGERS, P. (2008) The Everyday Resilience of the City: How Cities Respond to Terrorism and Disaster. London: Palgrave Macmillan.

COWELL, M. M. (2013) Bounce back or move on: Regional resilience and economic development planning. Cities, v. 30. pp.212-222.

DARNHOFER, I. (2014) Resilience and why it matters for farm management. European Review of Agricultural Economics (in press).

DAVOUDI, S. (2012) Resilience: a bridging concept or a dead end? Planning Theory \& Practice, v. 13. pp. 299-307.

DAWLEY, S.; PIKE, A.; TOMANEY, J. (2010) Towards the resilient region? Local Economy, v. 25, n. 8. pp. 650-667.

FICENEC, S. (2010) Building Regional Economic Resilience: What Can We Learn from Other Fields? Building Resilient Regions Network. Berkeley, University of California, working paper $\mathrm{n}^{\circ}$ 6. pp. 1-36.

FOLKE, C., et al. (2010) Resilience thinking: integrating resilience, adaptability and transformability. Ecology and Society, v. 15, n ${ }^{\circ}$ 4, art. 20.

FORD, A.; EMERY, K. F. (2008) Exploring the legacy of the Maya forest. Journal of Ethnobiology, v. 28. pp. 147-153.

FOSTER, K. A. (2007) A Case Study Approach to Understanding Regional Resilience. Working Paper 2007-08, Institute of Urban and Regional Development, University of California. pp. 1-45.

HASSINK, R. (2010) Regional resilience: a promising concept to explain differences in regional economic adaptability? Cambridge Journal of Regions, Economy and Society, v.3. pp.45-58.

HILL, E. W.; WIAL, H.; WOLMAN, H. (2008) Exploring Regional Economic Resilience. Working Paper 2008-04, Institute of Urban and Regional Development, University of California. pp. 1-16. 
HOLLING, C. S. (1973) Resilience and stability of ecological systems. Annual Review of Ecology and Systematics, v. 4. pp. 1-23.

HOPKINS, R. (2008) The Transition Handbook: From Oil Dependency to Local Resilience. Chelsea Green Publishing.

HUDSON, R. (2009) Resilient regions in an uncertain world: wishful thinking or a practical reality? Cambridge Journal of Regions, Economy and Society, v. 3. pp. 1125.

JANSSEN, M. A. (2007) An update on the scholarly networks on resilience, vulnerability, and adaptation within the human dimensions of global environmental change. Ecology and Society, v. 12, $\mathrm{n}^{\mathrm{o}} 2$.

LEBEL, L. et al. (2006) Governance and the capacity to manage resilience in regional social-ecological systems. Ecology and Society, v. 11, nº 1, art. 19.

MANYENA, S. B. (2006) The concept of resilience revisited. Disasters, v. 30, no 4. pp. $433-450$.

MARTIN, R. (2012) Regional economic resilience, hysteresis and recessionary shocks. Journal of Economic Geography, v. 12. pp. 1-32.

MÉNDEZ, R. (2002) Innovación y desarrollo territorial: algunos debates teóricos recientes. Revista Eure, Santiago de Chile, v. 28, nº 84. pp. 63-83.

. (2012) Ciudades y metáforas: sobre el concepto de resiliencia urbana. Ciudad y Territorio: Estudios Territoriales, v. 44, nº 172. pp. 215-231.

PECQUEUR, B. (2005) O desenvolvimento territorial: uma nova abordagem dos processos de desenvolvimento para as economias do sul. Raízes, Campina Grande, v. $24, \mathrm{n}^{\text {os }} 01$ e 02 . pp. 10-22.

PENDALL, R., FOSTER, K. A.; COWELL, M. (2009) Resilience and regions: building understanding of the metaphor. Cambridge Journal of Regions, Economy and Society, v. 3. pp. 71-84.

PIKE, A.; DAWLEY, S.; TOMANEY, J. (2010) Resilience, adaptation and adaptability.Cambridge Journal of Regions, Economy and Society, v. 3. pp. 59-70.

SANTOS, F. T. dos. (2009a) Territórios resilientes enquanto orientação de planeamento. Prospectiva e Planeamento, Lisboa, nº16. pp. 13-28.

(2009b) Resiliência estratégica para um desenvolvimento regional sustentável. Revista Portuguesa de Estudos Regionais, $\mathrm{n}^{\circ}$ 20. pp. 29-40.

SIMMIE, J.; MARTIN, R. L. (2010) The economic resilience of regions: towards an evolutionary approach. Cambridge Journal of Regions, Economy and Society, v. 3. pp. 27-43.

THE RESILIENCE ALLIANCE. (2007) Assessing and managing resilience in social-ecological systems: A practitioners workbook.Version 1.0, June, 81 p.

WALKER, B, et al. (2002) Resilience management in social-ecological systems: A working hypothesis for a participatory approach. Conservation Ecology, v.6, $\mathrm{n}^{\circ} 1$, art. 14.

WALKER, B. et al. (2004) Resilience, adaptability and transformability in socialecological systems.Ecology and Society, v. 9, n 2, art. 5. 
WALKER, B. et al. (2009) Resilience, adaptability, and transformability in the Goulburn-Broken Catchment, Australia. Ecology and Society, v. 14, n 1, art. 12.

Data de submissão: 07/07/2015.

Data de aceite: 11/12/2015. 